\title{
El cuidado en la familia
}

\section{The Care in the Family}

\author{
Tomás Melendo Granados \\ Catedrático de Filosofía (Metafísica) \\ Director de los Estudios en Ciencias para la familia \\ Universidad de Málaga \\ tmelendo@uma.es
}

\section{ResumeN $^{1}$}

El presente estudio muestra la afinidad existente entre la logoterapia y una antropología metafísica basada sobre el acto personal de ser. Examina la noción de "responsabilidad", que para Frankl constituye un atributo fundamental del ser humano. Y la relaciona con la visión onto-lógica del hombre, al hilo de tres de los trascendentales clásicos: verdad, bondad y belleza. Por fin, estudia la dependencia entre persona y familia y encuadra dentro de ella la realidad del cuidado.

Palabras clave: Frankl, logoterapia, antropología, metafísica, persona, responsabilidad, cuidado

\section{Abstract}

This paper shows the close relationship between Logotherapy and a metaphysical anthropology based on the personal act of being. It studies the idea of "responsibility", which Frankl considered a fundamental attribute of the human being. It also relates this idea to an ontological vision of man, following three of the classical transcendentals: truth, good and beauty. Finally, it studies the mutual dependence of the person and the family, which then becomes the framework for care.

Keywords: anthropology, care, Frankl, logotherapy, metaphysics, person, responsibility

\footnotetext{
${ }^{1}$ Comunicación presentada en las XIV Jornadas - Encuentro de la Asociación Española de Logoterapia (AeSLO), bajo el título "SENTIDO EN EL CUIDADO", celebradas en Madrid el 16 y 17 de octubre de 2010.
} 


\section{Planteamiento}

En este mi primer contacto "oficial" con la logoterapia querría mostrar ante todo, al hilo del tema que se me ha propuesto, las razones de mi acercamiento y mi aprecio hacia la escuela iniciada por Frankl.

Podrían reducirse a dos:

a) antes que nada, su propio valor intrínseco, que ustedes conocen mejor que yo;

b) en segundo término, y es este el único aspecto que pretendo desarrollar, la enorme afinidad con la metafísica que profeso, como docente e investigador, y como ser humano, en los distintos ámbitos en que se despliega mi existencia.

Y puesto que el punto de unión entre ambas cosmovisiones es la importancia concedida a la persona, también intentaré hacer ver, aunque sólo en escorzo, los lazos profundos que ligan la logoterapia al personalismo ${ }^{2}$ y a la metafísica del (acto de) ser, con la que me identifico.

Como es lógico, tal cúmulo de propósitos impide un tratamiento exhaustivo de ninguno de ellos. Me moveré, por tanto, casi por alusiones y, más en concreto, refiriendo algunos textos claves de Frankl a los desarrollos de mi comprensión del hombre a la luz de la Seinsmetaphysik. De tal modo, me propongo hacer ver que la sinergia a la que vengo aludiendo no es algo coyuntural ni artificioso, elaborado ad casum, en función del contexto de cultivadores y amantes de la logoterapia en que ahora me encuentro, sino una verdad que se me ha ido imponiendo a lo largo de muchos años y ha quedado reflejada en mis escritos.

No debería extrañar, por este motivo, que, contra el uso habitual en los ensayos científicos, sobreabunden las referencias a textos publicados por el autor de estas líneas. ${ }^{3}$

\subsection{Uno de los centros neurálgicos de la logoterapia}

Como punto de partida del planteamiento frankliano tomaré lo que, robando la expresión a un pensador también contemporáneo, podría denominarse "principio de

\footnotetext{
${ }^{2}$ Sólo a modo de ejemplo: «Insofern, als die Logotherapie sich gerade nicht an das Symptom wendet, sondern einen Einstellungswandel, eine personale Umstellung gegenüber dem Symptom herbeizuführen ersucht, ist sie echte personalistische Psychotherapie». FrankL, Viktor: „Grundriß der Existenzanalyse und Logotherapie“ (1939); IDEm: Logotherapie und Existenzanalyse: Texte aus sechs Jahrzehnten. Weinheim und Basel: Beltz Verlag, 2002, S. 172.

${ }^{3}$ Insisto en este punto, porque lo considero de especial relevancia. Aunque los usos académicos invitan a eludir las citas de quien escribe, en este caso pienso que lo que pretendo mostrar perdería buena parte de su fuerza si, en lugar de la transcripción literal de mis afirmaciones, las limitara a un simple cf.
} 
responsabilidad". ${ }^{4}$ Estimo que no se trata de un inicio arbitrario, por cuanto el propio Frankl considera la responsabilidad como elemento vertebrador del ser humano, tanto cuando lo estudia de manera teórica como en la propia práctica terapéutica. ${ }^{5}$

Me limito a algunas citas fundamentales, elegidas casi al azar entre muchas posibles. Por ejemplo, ya en un artículo publicado en $1938^{6}$ encontramos las siguientes expresiones, definitorias del hombre en cuanto tal:

[...] una consideración general de los fundamentos más profundos de la existencia humana da como resultado la siguiente fórmula antropológica: ser yo significa ser consciente y ser responsable. ${ }^{7}$

$\mathrm{O}$, de manera aún más expresa, por cuanto se la declara un rasgo "central" o constitutivo de cualquier mujer o varón:

En efecto, partíamos de que el ser responsable y el ser consciente (en su nivel de evidencia obvia) constituyen juntos la existencia humana. Pero la responsabilidad de la persona humana, considerada como concepto antropológico fundamental...8

\footnotetext{
${ }^{4}$ Me refiero al libro que hizo célebre a Hans Jonas. A saber, Jonas, Hans: Das Prinzip Verantwortung: Versuch einer Ethik für die technologische Zivilisation. Frankfurt am Main: Insel Verlag, 1979 (tr. cast.: El principio de responsabilidad: Ensayo de una ética para la civilización tecnológica. Barcelona: Herder, 1995).

${ }^{5}$ Sirva como confirmación el autorizado testimonio de Fizzotti. En el tan esclarecedor Prólogo a la edición crítica de los Frühe Schriften. 1923-1942, al referirse a los escritos en los que Frankl comienza a señalar la que luego será su postura definitiva, en el parágrafo que titula "La imagen del hombre en el joven Frankl”, sostiene sin ambages: «Der Ausgangspunkt war eindeutig seine Überzeugung, daß „Ich-sein [...] Bewußt-sein und Verantwortlichsein“ heißt». Fizzotтı, Eugenio: „Einladung zur Lektüre der Schriften des jungen Frankl“; FrankL, Viktor E.: Frühe Schriften. 1923-1942. Herausgegeben von Gabriele Vesely-Frankl. Mit einem Vorwort von Eugenio Fizzotti. Wien; München; Bern: Verlag Wilhelm Maudrich, 2005, S. 13 (tr. cast.: Escritos de juventud. 1932-1942. Gabriele VaselyFrankl (ed.). Prólogo de Eugenio Fizzotti. Barcelona: Herder, 2007, p. 21).

${ }^{6}$ Que yo sepa, la primera mención expresa y un tanto desarrollada de la responsabilidad como elemento esencial del ser humano se encuentra en el artículo de 1927: "Liebe und Verantwortlichkeit" (Sachlichkeit (15.1.27) 2, [1927], Nr. 1, S. 3-4). Von med. Viktor Frankl (Wien). FrankL, Viktor E.: Frühe Schriften. 1923-1942, cit. S. 55-56.

${ }^{7}$ FrankL, Viktor: „Zur geistigen Problematik der Psychotherapie“; in Frühe Schriften. 1923-1942, cit., S. 165 (tr. cast.: "Problemática espiritual de la psicoterapia"; Escritos de juventud. 1923-1942, cit., p. 240).

${ }^{8}$ FrankL, Viktor: „Zur geistigen Problematik der Psychotherapie“, cit., S. 169 (tr. cast., pp. 245-246). Las cursivas de la cita (concepto antropológico fundamental) son mías.

En el mismo artículo, después de las anteriores afirmaciones, Frankl señala expresamente algunos de los autores que la avalan: «Diese Auffassungen lassen sich von vielen Seiten her durch ähnlich lautende belegen. Jaspers spricht etwa vom „Sein als entscheidendem Sein”; Pfeiffer, in seinem Büchlein über Heidegger und Jaspers, bezeichnet ausdrücklich die „Verantwortlichkeit als Letztes". Im Besonderen hinsichtlich der Psychotherapie definierte Allers einmal (in einem Vortrag) die Psychotherapie als „Erziehung zur Anerkennung der Verantwortlichkeit". Und Kronfeld, der sich des oben besprochenen Dilemmas wohl bewußt ist, fordert, daß der Neurotiker „sich selbst gegenüber erhöht verantwortlich” werde. In Bezug auf die angedeutete Grenzsetzung für die wertende Psychotherapie verlangt I.H. Schultz, daß „der Kranke durch die Arbeit des Arztes ein Mensch werde eigenen Wesens, eigener Welt, eigener Verantwortung”. Und auch Meinertz wünscht: „,... nicht bestimmte Werte aufzeigen, bekehren; sondern helfen, zu seinen Werten, seiner Persönlichkeit angemessenen Möglichkeiten durchzustoßen”. Ganz klar formuliert Oswald Schwarz den Sachverhalt (in einem privaten Schreiben): „Wir geben Haltungen und nie Inhalte.”» FranKL, Viktor: „Zur geistigen Problematik der Psychotherapie“, cit., S. 169 (tr. cast., pp. 246-247). Las cursivas de la cita son mías.
} 


\section{O, en el mismo artículo, pero ahora en contexto de práctica terapéutica, indican-} do la médula que guía esa praxis:

En determinadas circunstancias se hará necesario sobre todo explicar la responsabilidad como un rasgo fundamental de la existencia humana de tal modo que pueda ser comprendida por el hombre sencillo, es decir, en un lenguaje cotidiano lo más concreto posible, que en ciertos casos no debe tener reparo en recurrir a la utilización de comparaciones apropiadas. ${ }^{9}$

Se trata, como decía, de convicciones recurrentes en toda la producción de Frankl, que aparecen también en otros escritos de finales de los treinta, ${ }^{10}$ que encuentran una formulación bastante completa en su obra más conocida -El hombre en busca de sentido- y en las que la siguen; y que, además, está ligada a otros elementos centrales de la logoterapia: el sentido, los valores, la estricta unicidad de cada ser humano, la misión que por tanto se encomienda a cada uno, la autotrascendencia...

Divido la cita en dos partes por razones pedagógicas. En primer término, Frankl realiza una corrección profunda a ciertas actitudes comunes en su tiempo y en el día de hoy:

En última instancia, el hombre no debería cuestionarse sobre el sentido de la vida, sino comprender que la vida le interroga a él. En otras palabras, la vida pregunta por el hombre, cuestiona al hombre, y este contesta de una única manera: respondiendo de su propia vida y con su propia vida. Únicamente desde la responsabilidad personal se puede contestar a la vida.

De inmediato, expone de forma casi solemne y lapidaria el principio que intento poner de relieve:

\footnotetext{
${ }^{9}$ FrAnKL, Viktor: „Zur geistigen Problematik der Psychotherapie“, cit., S. 170 (tr. cast., p. 248).

${ }^{10}$ Por ejemplo, en „Seelenärtztliche Selbstbesinnung“ (1938), donde se advierte el influjo del Sollen kantiano, como fundamento ético meramente formal, carente de ningún contenido concreto: «Wir stehen also in der Psychotherapie, soweit sie werten muß oder soll, vor einem Dilemma: Auf der einen Seite die unerbittliche Notwendigkeit, Weltanschauung und damit Wertproblematik in sie hineinzutragen; auf der anderen Seite aber gleichzeitig die unausweichliche Forderung, jeden Oktroi zu vermeiden! Ich selbst habe nun versucht (vgl. „Zur geistigen Problematik der Psychotherapie", Zentralblatt für Psychotherapie, 1937), dieses Dilemma zu beheben. Es ist dazu nur nötig, auf einen Wert zurückzugreifen, der als rein formaler ethischer Wert noch keine Richtung auf konkrete Werte impliziert: auf den Wert der Verantwortlichkeit! Es läßt sich ja kein Wertsystem, keine persönliche Wertrangordnung, keine private Weltanschauung denken, die nicht Verantwortlichkeit als grundlegenden Wert anerkennen müßte, als formalen Wert gegenüber inhaltlich verschiedenen Bestimmungen; uns Psychotherapeuten darf gar nicht daran gelegen sein, welche weltanschaulichen Bekenntnisse unsere Patienten haben, welche Werte sie wählen; was not tut, ist aber, die Kranken so weit zu bringen, daß sie Weltanschauung schlechthin haben, und daß sie überhaupt Werten gegenüber sich verantwortlich fühlen. In welch bedeutendem Maße ein solches Hinführen des seelisch Leidenden zur eigenen Verantwortlichkeit therapeutisch geradezu ein Hebelpunkt werden kann, darauf allerdings kann und soll auch in diesem Rahmen gar nicht erst eingegangen werden». FRANKL, Viktor: "Seelenärtztliche Selbstbesinnung“ (Der Christliche Ständestaat, 5 [1938], S. 72-74); IDEM: Frühe Schriften. 1923-1942, cit., S. 180 (tr. cast.: “Reflexión de la psicoterapia sobre sí misma"; Escritos de juventud. 1923-1942, cit., pp. 261-262). Cursivas mías.
} 
De tal modo que la logoterapia considera que la esencia de la existencia consiste en la capacidad del ser humano para responder responsablemente a las demandas que la vida le plantea en cada situación particular. ${ }^{11}$

\section{Un elemento más bastaría para dibujar, sumariamente, la importancia de la "res-} ponsabilidad" en el conjunto de la logoterapia. Me refiero al principio terapéutico básico, en virtud del cual el terapeuta jamás debe asumir la responsabilidad de las decisiones del paciente, sino más bien hacer que este sea consciente de la que le corresponde como ser humano y actúe en consecuencia:

El logoterapeuta se guardará mucho de que el paciente cargue sobre él la responsabilidad porque la logoterapia esencialmente es educación a la responsabilidad. Desde esta responsabilidad, el enfermo debe penetrar autónomamente hasta el sentido concreto de su existencia personal. [...] El análisis existencial debe llevar al hombre a la conciencia de su responsabilidad; pero, además de esto, no se le deben proporcionar valores concretos de ningún tipo, sino que más bien se debe limitar a hacer que el paciente encuentre de manera autónoma los valores que de él esperan su realización y el sentido que de él aguarda un cumplimiento. Lo que, en cambio, en ningún caso se puede hacer es una imposición al paciente del orden de rango de los valores y de la visión del mundo del terapeuta, una transferencia cosmovisiva. ${ }^{12}$

La capacidad de elevar al hombre inscrita en ese asumir la propia condición responsable es otra constante en los escritos de Frankl. Y, así, por ejemplo, ya en 1939 afirma:

Nada hace superar al hombre tanto, nada es capaz de activarlo más, nada le hace superar las molestias o dificultades tanto, como la conciencia de la responsabilidad personal, la experiencia vivida de su misión especial. Y aquí reside la utilidad psicoterapéutica incomparable y exquisita de un análisis de la existencia como ser responsable, de un análisis del ser hombre respecto a su característica esencial, respecto al ser responsable. ${ }^{13}$

\footnotetext{
${ }^{11}$ Levemente contextualizado: «As each situation in life represents a challenge to man and presents a problem for him to solve, the question of the meaning of life may actually be reversed. Ultimately, man should not ask what the meaning of his life is but rather he must recognize that it is he who is asked. In a word, each man is questioned by life; and he can only answer to life by answering for his own life; to life he can only respond by being responsible. Thus, logotherapy sees in responsibleness the very essence of human existence». FRANKL, Viktor: Man's Search for Meaning. New York: Pocket Books, 1988, p. 130 (tr. cast.: El hombre en busca de sentido. Barcelona: Herder, 2004, pp. 130-131). Las cursivas del segundo párrafo (la esencia de la existencia y responder responsablemente) son mías.

${ }^{12}$ FrankL, Viktor: „Grundriß der Existenzanalyse und Logotherapie“ (1939); Logotherapie und Existenzanalyse: Texte aus sechs Jahrzehnten, cit., S. 151-152 (tr. cast.: "Elementos del análisis existencial y de la logoterapia"; Logoterapia y análisis existencial: Textos de cinco décadas, cit., p. 161).

${ }^{13}$ FrankL, Viktor: „Philosophie und Psychotherapie. Zur Grundlegung einer Existenzanalyse“ (1939); Logotherapie und Existenzanalyse: Texte aus sechs Jahrzehnten, cit., S. 44 (tr. cast.: "Filosofía y psicoterapia. Fundamentación de un análisis existencial"; Logoterapia y análisis existencial: Textos de cinco décadas, cit., p. 47).
} 
No extraña, por eso, que Fizzotti, uno de los principales especialistas en el pensamiento de Frankl, ya citado, subrayara en 1977 que el principio supremo de la logoterapia pivota en torno a la responsabilidad. ${ }^{14}$

\subsection{Su similitud con la "Seinsphilosophie"}

Como apunté, sin forzar en absoluto ni los textos ni los contextos, el que antes denominaba "principio de responsabilidad" puede considerarse asimismo el fundamento de la antropología que se basa en una auténtica y no reduccionista ni abstracta metafísica del ser, centrada, por tanto, en cada persona singularísima y eminentemente digna, a la que ese ser corresponde en un grado sobreeminente. ${ }^{15}$

En los escritos del fundador de la logoterapia no son pocas las referencias implícitas o explícitas a Heidegger, con quien Frankl mantuvo un trato también directo y cuya filosofía le resultaba bien conocida. Pues bien, en la misma caracterización heideggeriana del Da-sein como el "ahí del ser" late una idea que recorre la descripción metafísica del hombre más reiterada a lo largo de la historia del pensamiento

14 «Per la logoterapia la vera essenza della vita sta nella responsabilità. Responsabilità verso le cose, le persone, le idee. Verso i figli, i genitori, gli insegnanti. Una responsabilità non identica per tutti, ma diversa per ognuno; una responsabilità che varia da persona a persona, e da situazione a situazione. E quindi, anche per curare la nevrosi e la depressione, la cosa piú importante è il compito per il quale ognuno deve lottare nella propria vita. Ciò vale molto di più del denaro, del successo, del piacere». Fizzotrı, Eugenio: "Presentazione"; in FrankL, Viktor E.: Alla ricerca di un significato della vita: Una guida efficace e sicura che può aiutarci a risolvere i nostri problemi. 4 a ristampa. Traduzione dal tedesco di Eugenio Fizzotti condotta sull'edizione pubblicata dalla Herder Verlag col titolo Der Mensch auf der Suche nach Sinn (Titolo originale dell'opera: Das Menschenbild der Seelenheilkunde). Milano: Mursia, 2007, pp. 10-11.

${ }^{15} \mathrm{Al}$ respecto, y como muestra del personalismo de Frankl, es sumamente significativo, también por la fecha temprana en que fue redactado, este texto, en el que describe la actitud que debe presidir lo que entonces era su actividad más querida: Los centros de asesoramiento juvenil. Ya en 1929 escribía: «Der rechte Jugendberater kennt eigentlich keine „Fälle”. Noch weniger kennt er typische Fälle. Denn er stellt sich grundsätzlich zu den jungen Menschen, die ihn im Rahmen seiner Tätigkeit als Jugendberater aufsuchen, nicht wie zu einem „Fall” ein: als Arzt faßt er den jungen Menschen nicht als Patienten auf; als Jurist empfängt er ihn nicht als Klienten, als Fürsorger nicht als Petenten; sondern von vornherein sieht er in ihm nur den Menschen, einen Menschen, der ganz zufällig und schuldlos in eine bedrängte Situation gelangt ist, aus der er alleine nicht so leicht heraus findet. Er ist eben noch jung und weiß nichts von der einen oder der anderen Möglichkeit einer Abhilfe, von diesem oder jenem Ausweg. Da soll ihm eben der Jugendberater beistehen und einen Weg weisen. So tausendfältig die Menschen und Situationen, so tausendfältig ihre Not und der richtige Rat. Daher kann man nur bedingt von "typischen Fällen” sprechen». FrankL, Viktor: „Typische „Fälle” aus der Jugendberatung” (Zeitschrift für Kinderschutz, Familien- und Berufsfürsorge, 21 [1929] Nr. 11, S. 163-164); IDEm: Frühe Schriften. 1923-1942, cit., S. 112 (tr. cast.: "Casos' típicos del asesoramiento juvenil"; Escritos de juventud. 1923-1942, cit., p. 162). 
occidental, al menos desde Heráclito ${ }^{16}$ y Parménides. ${ }^{17}$ El hombre, vienen a decir nuestros mejores filósofos, es aquel ser peculiarísimo, cuya apertura a la realidad hace posible que ésta se le presente precisamente como real, como lo que ella es y no como simple estímulo para la supervivencia de quien la conoce.

Se trata, sin duda, de una expresión nada fácil, pero que puede esclarecerse mediante ejemplos relativamente sencillos, que señalan la diferencia entre el hombre y los animales. ${ }^{18}$ Por las razones antes aducidas - mostrar la afinidad entre antropología metafísica y logoterapia-, esbozo este panorama utilizando como fuente principal dos de mis escritos: un libro cuya primera edición se remonta a 1992 y que aborda el análisis del ser humano como «principio y término de amor»; ${ }_{1}^{19} \mathrm{y}$ otro, algo más tardío, que versa fundamentalmente sobre la felicidad. ${ }^{20}$

\section{En el primero de ellos decía:}

Y de ahí nace la distinción radical entre el hombre y los animales. Considerarla con cierto detalle - contraponiendo lo que compete a uno y a otros- puede representar una manera inmejorable de acabar de advertir al hombre como principio y término de amor.

Para intentarlo, acudiré a doctrinas conocidas, que enlazan a Aristóteles y la tradición medieval aristotélica con la antropología fenomenológica de nuestro siglo: Gehlen y Plessner, por citar solo dos nombres. Estos últimos han expresado esa discrepancia diciendo que el animal tiene perimundo (Umwelt), mientras que el hombre tiene mundo (Welt); y que, por este motivo, la persona humana puede calificarse como un ser ex-céntrico: es decir, un ser que no se constituye en eje alrededor del cual hace girar todo lo restante; un ser que no pretende imponer al

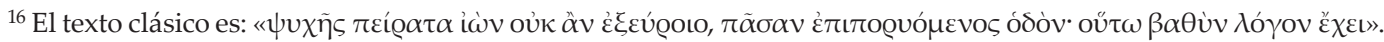
Die Fragmente der Vorsokratiker. Griechisch und Deutsch von Hermann Diels. Herausgegeben von Walther Kranz. Erster Band. ${ }^{16} 1972$, unveränderte Nachdrucke der 6. Auflage (6. Aufl., 1951). Dublin; Zürich: Weidmann. 1972, B 45 [71], S. 161.

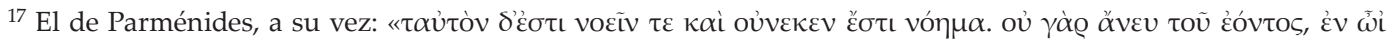

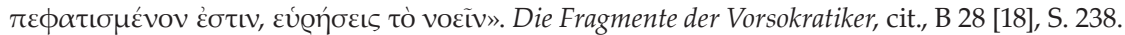

18 También la actitud que lleva a perfilar lo propio del ser humano por comparación con los animales es una constante de la historia del pensamiento, al menos desde Aristóteles. En nuestros días, entre otros muchos, de una manera sugerente y simpática, la defiende Kass: «At the center of any philosophical anthropology will be an account of the human difference, of what is peculiarly human about human nature and the human animal. [...] But to know the human, if only by contrast and relation, we need to know also the nonhuman, especially the animal. For though we may be, as claimed in many traditions, the most godlike of the animals, we live always an animated and necessitous existence just like our fellow animals. Yet because modern biology with its materialistic and mechanistic biases fails to do justice to the evident vitality of animal life, it will fail also to do justice to our humanized animality». KAss, León R.: The Hungry Soul: Eating and the Perfecting of Our Natures. With a new Foreword. Chicago and London: The University of Chicago Press, 1999 (1 $1^{\text {st }}$ ed., 1994), p. XV.

${ }^{19}$ Melendo, Tomás: Ocho lecciones sobre el amor humano. $4^{\mathrm{a}}$ ed., ampliada. Madrid: Rialp, 2002. Traducido al italiano $\left(1998^{1}, 2008^{2}\right)$. Publicado también en México: Ocho lecciones sobre el amor humano: más allá de la unión afectiva. México D. F.: Trillas. 2008. Las citas corresponden a esta última edición.

${ }^{20}$ También en este caso los tomo literalmente de otro de mis escritos: Melendo, Tomás: Felicidad y autoestima. Madrid: Ediciones Internacionales Universitarias, 2006 ${ }^{1}, 2007^{2}$, corregida y aumentada. IDEM: El "efecto" felicidad: amor y perfeccionamiento humano. México D. F.: Trillas, 2008.
} 
universo que lo circunda el significado subjetivo que la realidad tiene para él; o, si se quiere, un ser que, merced a su capacidad de relativizar los propios instintos, sabe reconocer teórica y vitalmente a otros posibles "centros" - también virtualmente excéntricos - del cosmos: es decir, a otras personas.

De manera más sencilla, cabría afirmar que el animal posee solo perimundo porque es incapaz de conocer aquellas realidades, y aquellas facetas de la realidad, que carecen de un significado inmediato para su dotación instintivo-vital, al no resultarle ni beneficiosas ni dañinas. No se trata solo de que no "le interese", sino que ni tan siquiera percibe cuanto no afecte de forma directa a su bienestar. Es decir, solo capta algunos de los seres que lo rodean y, dentro de ese ámbito limitado, únicamente advierte los aspectos relacionados con su haz de instintos (y esa doble limitación determina su perimundo).

\section{En el libro sobre la felicidad ejemplificaba, centrándome primero en el cono- cimiento:}

[...] acudiendo a observaciones que se hunden en lo más remoto de los siglos, para el cordero recién nacido la oveja madre es advertida fundamental y casi exclusivamente como fuente de alimentación (como lactabile, que decían los medievales): esto es, en función del beneficio que a él le produce. El lobo, por su parte, le resulta aprehensible solo como un peligro del que hay que huir (como fugiendum, en la terminología latina): es decir, una vez más, en dependencia del daño que tiende a provocarle.

Ninguna de estas dos realidades - oveja madre o lobo- es conocida por nuestro corderito como algo autárquico, consistente, con un modo de ser y unas características concretas y definitorias por sí mismas, y que además le resulta provechoso o dañino: sino que el animal los percibe únicamente desde ese "además", desde la perspectiva de su propia utilidad o perjuicio.

Y de ahí, como decía, que aquellos otros seres - vivos o inertes - que ni lo favorecen ni lo dañan, de ningún modo entren en su campo de percepción: para él, no existen (y, por tanto, es imposible que los perciba).

Como consecuencia, y trascendiendo la estrechez del ejemplo, al ejercer su actividad, los animales irracionales se moverán también, exclusivamente, atendiendo a su propia conveniencia y ventaja; perseguirán lo que para cada uno de ellos se ofrezca como provechoso, y huirán de lo que, también para cada uno, se muestre perjudicial; es decir, obrarán a tenor del puntiforme y exclusivo bien o mal para sí (o para su especie, en cuanto que es la suya).

\section{Después añadía, considerando también cuanto atañe a los apetitos sensibles y a} la voluntad:

En conclusión, tanto desde el punto de vista del conocimiento como del de los apetitos, el animal goza solo de peri-mundo: de un conjunto parcial de fragmentos de realidad, remitidos de forma determinante a su propia dotación instintiva, que es la que los re-inventa o re-crea y les confiere significado.

Desde nuestro punto de vista: al carecer de inteligencia y voluntad, ni pueden entender la razón de bien que existe en la realidad y en algunas actividades, ni son capaces de desear otros "bienes" que los que para ellos resulten tales: pues las tendencias sensibles tienen un objeto determinado, y no aspiran al bien universal o en cuanto tal. 
Además, y esto es clave, al no percibir la razón de bien-en-sí, no son movidos propiamente por el objetivo de su deseo (que no pueden advertir como bien), sino por el placer que su consecución les reporta, lo único capaces de experimentar gustosamente.

La conclusión es la antes apuntada: a diferencia del animal, que en sentido estricto no ama, el hombre se configura como "un-ser-para-el-amor", orientado hacia los demás ${ }^{21} \mathrm{y}$, por este mismo motivo, merecedor de ser amado.

\section{La filosofía primera (o metafísica) como sabiduría}

\subsection{Animal ontológico o metafísico}

Más allá de la conocida doctrina que, en atención a su etimología y a la actitud del verdadero filósofo, califica la philosophia como amor o anhelo de un auténtico saber, al apelar aquí a la sabiduría pretendo oponerme a una afirmación que se ha hecho clásica, pero que estimo equivocada. Contra lo que habitualmente se piensa, el metafísico, el amante de la sabiduría, no es un simple "teórico" dedicado a especular al margen de la vida vivida. Es más bien una persona que busca el conocimiento de cuanto lo rodea, en primer término, porque esa realidad "lo merece" y "lo reclama", pero también para orientar su propia vida y ayudar a los demás a hacer otro tanto.

Por tanto, la metafísica es a la par teorética y sumamente práctica. ${ }^{22} \mathrm{Y}$ lo es, además, por su propia índole de saber primero, aunque muchos a lo largo de su historia lo hayan ignorado o incluso se opongan de forma expresa a tal caracterización.

Suelo explicarlo diciendo que, frente a la actitud de las ciencias experimentales, que por naturaleza y en función del propio método, atienden tan solo a ciertos as-

\footnotetext{
${ }^{21}$ No es necesario advertir la estrecha afinidad entre este modo de mostrársenos el hombre y la autotrascendencia frankliana. He aquí uno de sus textos más claros: «Wenn diesbezüglich eines feststeht, dann ist es das folgende. Bloßes Überleben kann nicht der höchste Wert sein. Mensch sein heißt, ausgerichtet und hingeordnet sein auf etwas, das nicht wieder es selbst ist. Menschliche Existenz ist charakterisiert durch ihre Selbsttranszendenz. Sobald menschliches Dasein nicht mehr über sich selbst hinausweist, wird Am-Leben-bleiben sinnlos, ja unmöglich. Dies war zumindest die Lehre, die mir in 3 Jahren zuteil wurde, die ich in Auschwitz und Dachau verbringen mußte, und inzwischen konnten Militärpsychiater in aller Welt bestätigen, daß jene Kriegsgefangenen noch am ehesten fähig waren zu überleben, die auf die Zukunft hin orientiert waren, auf ein Ziel in der Zukunft, auf einen Sinn, den in der Zukunft zu erfüllen es galt. Sollte Analoges nicht auch dort gelten, wo es um die Menschheit und deren Überleben geht?» FrankL, Viktor E.: Der leidende Mensch: Anthropologische Grundlagen der Psychotherapie. 2. Aufl. Bern: Verlag Hans Huber, 1984, S. 41.

${ }^{22} \mathrm{Al}$ respecto, sostiene Cardona: «La sabiduría es ciencia, en el sentido aristotélico del término: conocimiento cierto por causas, pero aquí ya por causas últimas. En este sentido, la filosofía es ciencia; pero como las causas que busca son últimas, su conocimiento afecta al "hacer" del hombre como tal. Es ciencia teórico-práctica, es sabiduría: ciencia que da a conocer la realidad del ser, de todo cuanto es y ha de ser según lo que es y en la misma medida normatiza: se derivan de modo inmediato consecuencias prácticas». CARdona, Carlos: Ética del quehacer educativo. 2ª ed. Madrid: Rialp, 2002, p. 22.
} 
pectos de un ámbito restringido de lo real, de ordinario para utilizar instrumentalmente - con vistas a su propia utilidad - las realidades que así conocen, el filósofo genuino se abre a la totalidad de lo existente, sin preclusiones ni defensas, para dejarse invadir por ella y obrar en función de lo que, en sus circunstancias particulares y nunca repetibles, esa realidad le demande.

Y, de ordinario, expongo los rasgos del "obrar humano responsable" al hilo de lo que la metafísica clásica denomina "trascendentales", que corresponden a la caracterización del hombre como ser onto-lógico.

Así, en el libro en torno al amor que antes citaba, tras esbozar el comportamiento propio de los animales, añadía:

Como vislumbró Heidegger, el hombre es un ser onto-lógico, capaz de captar al ente como tal o, si se prefiere, a la realidad como es en sí - aunque de forma imperfecta-, y no forzosamente en dependencia del daño o provecho que a él pueda ocasionarle.

Por eso dicen los clásicos que es capax entis, apto para aprehender la condición de real que constituye a cuanto lo circunda (y a él mismo). Pues bien [...], en la misma medida en que resulta capax entis, el hombre se configura también como capax boni, como "abierto" al bien real, objetivo.

Agregaba a continuación lo que ya sabemos, pero en un contexto diversamente matizado:

Relativizando o poniendo entre paréntesis el bien-para-sí que reclaman sus "instintos", el ser humano puede conocer y querer el bien en cuanto tal, el bien en sí y, por ende, el bien del otro en cuanto otro. Y no solo percibirlo y quererlo, sino procurarlo positivamente y, si cabe hablar de este modo, "construirlo", darle vida.

Para concluir de inmediato con una afirmación también sabida y sobre la que volveré más tarde:

Constitutivamente, en oposición al animal, el hombre es altruista, está abierto e inclinado hacia el bien de los otros: sabe y tiende a amar. ${ }^{23}$

\footnotetext{
${ }^{23}$ Estamos de nuevo ante una tesis muy cercana a las de Frankl: «Pero no sólo no se puede hacer una autorreflexión completa, sino que tampoco se debe hacer; pues no es la tarea del espíritu el observarse a sí mismo y el mirarse a sí mismo en el espejo. jForma parte de la esencia del hombre su ser orientado hacia, sea hacia alguna cosa, sea hacia alguien, sea hacia una obra, sea hacia un hombre, hacia una idea o hacia una persona! Y sólo en la medida en la que somos intencionales, somos existenciales; sólo en la medida en que el hombre está espiritualmente con algo o con alguien, junto a otro ente espiritual así como junto a un ente no espiritual, sólo en la medida de tal "estar junto a", el hombre está consigo mismo. El hombre no existe para observarse a sí mismo ni para mirarse a sí mismo en el espejo; sino que existe para entregarse, para sacrificarse y para abandonarse conociendo y amando». FrANKL, Viktor: „Grundriß der Existenzanalyse und Logotherapie“, cit., S. 80-81 (tr. cast., p. 86).
} 


\subsection{El ente como verdadero}

Por los motivos ya reiterados, acudo ahora a otra publicación, ${ }^{24}$ en la que despliego con más detenimiento mi propia concepción de tres de los trascendentales clásicos: verdad, bondad y belleza.

En ella, al referirme a la "verdad" de lo real, y bajo el título "la primera exigencia de cuanto existe", sostengo que «el ente en cuanto tal pide ser conocido». ${ }^{25}$ Muy poco después, en la misma línea en la que Frankl alude a una realidad que interroga al hombre para que este le responda, añado que la primera "respuesta" que el hombre "debe" a la realidad es justo el conocerla en la medida en que esta lo reclama:

Su inicial y más básica apelación al ser humano, provista de todo el vigor de un auténtico imperativo ético, podría expresarse como sigue:

“¡Escúchame!, jatiéndeme!, ¡conóceme!... que para algo soy. Y, porque soy, poseo una consistencia susceptible de esclarecimiento cognoscitivo. No me desprecies, refugiándote en el recurso subjetivista de la mera opinión. Hay cosas acerca de mí que pueden saberse con certeza; y, por lo mismo que pueden, deben ser conocidas de ese modo".

\section{Por lo que puedo concluir, de nuevo en consonancia con las tesis de Frankl:}

Respecto al sujeto humano, la verdad que compete al ente en cuanto que es no se traduce en mera inteligibilidad, en simple posibilidad de ser apreciado y desentrañado; sino que es una exigencia, un imperativo: todo ente reclama que se lo conozca en la misma medida en que es ente.

Agrego enseguida, también en íntimo acuerdo con el personalismo:

Más, por tanto, lo que posee un ser más noble y elevado. Por eso, en una cosmovisión que tome nota de la intrínseca consistencia de lo real, lo necesario postula una atención más esmerada que lo contingente, lo inmutable suscita más interés que lo sometido a cambio, lo eterno más que lo perecedero, lo permanente más que lo fugaz. [...] Toda persona, en lo que tiene precisamente de intemporal, se convierten entonces en centro prioritario de dedicación y esfuerzo. Muy por delante, como es obvio, de lo exclusivamente material, de lo que hoy se conoce como Naturaleza.

\section{Y concluyo:}

La norma podría ser la que sigue: intentar conocer cada realidad en la proporción exacta que reclama su ser, su consistencia interna.

\footnotetext{
${ }^{24}$ Melendo, Tomás: Metafísica de lo concreto: sobre las relaciones entre filosofía y vida... y una pizca de logoterapia. Madrid: Ediciones Internacionales Universitarias, 2009. La primera edición es de 1997. También existe traducción al italiano $\left(2000^{1}, 2002^{2}, 2005^{3}\right)$ y al portugués (2002).

${ }^{25}$ En esta como en las restantes citas de mis escritos, las cursivas se encuentran ya en el texto original: no han sido añadidas para mostrar la concordancia con el planteamiento logoterapéutico.
} 


\subsection{La "llamada" de lo bueno}

Más adelante, al reflexionar sobre la bondad que corresponde a cualquier ente en la misma proporción en que es, explico que, «en cuanto bueno, todo lo que es reivindica también una réplica, una contestación por parte del hombre, aunque de distinta naturaleza que la que solicita como verdadero».

Después, resumo la naturaleza de esa "respuesta" humana, articulándola en tres aspectos o "momentos":

a) Lo primero que pide lo bueno es que se lo apruebe, que nos adhiramos a él: también verbalmente, pero sobre todo con las fibras más íntimas de nuestro ser, con toda nuestra persona.

b) A continuación, lo que se encuentra dotado de bondad postula que se desee sinceramente su plenitud, su enaltecimiento perfectivo, el despliegue enriquecedor contenido en la energía primordial de su acto de ser.

c) Por fin, nuestra respuesta a lo bueno nos llevará, en la medida de lo posible, a apoyar ese desenvolvimiento de mejora con nuestra propia actividad, a cooperar con los hechos a que se desarrolle plenamente.

\section{De nuevo concluyo:}

Todo lo que disminuya el alcance de esta respuesta, por suprimir uno o más de sus elementos, equivale - en lo que está de nuestra parte- a rebajar la realidad en su constitutiva índole de ente-bueno.

$\mathrm{Y}$ aludo a un ejemplo entre muchos, que estimo significativo y esclarecedor, aunque tal vez "políticamente incorrecto":

Resulta obvio que el bombardeo informativo al que, con más o menos voluntariedad, se someten nuestros contemporáneos, acaba por inhibir en ellos la posibilidad de vibrar operativa, e incluso sentimentalmente, tal como exige la realidad que los circunda en virtud de su intrínseca bondad.

$\mathrm{Y}$, en consecuencia, puesto que ens y bonum se identifican, el universo deja de ser percibido y vivido como real.

Más adelante, tras analizar otras causas más profundas que también "inhiben" la respuesta humana a lo que la realidad le pide (es decir, la "responsabilidad" de la que vengo hablando y en la que Frankl se centra), retorno sobre el ejemplo citado y explico:

Como es lógico, ningún hombre tiene la obligación de responder con todas sus consecuencias a la bondad o malicia de cuanto los medios informativos ofrecen a su conocimiento. Su misma índole espacio temporal se lo impide. No van por ahí los tiros. Lo radicalmente peligroso es que la reiterada exposición a realidades ante las que no puede reaccionar promoviendo su bien o sofocando su mal, vaya atrofiando su misma capacidad de respuesta... y termine por comportarse frente a su entorno de idéntica forma a como se relaciona con lo que está fuera de su 
ámbito de acción. Multitud de estudios experimentales muestran que este proceso ha afectado a buena parte de nuestros conciudadanos.

Y es normal. El niño expuesto durante años a millares de escenas de violencia que no solo no repudia, sino que acaba incluso por aprobar y buscar; el adulto que ve desfilar ante él cada día, en el telediario, atrocidades que exigirían una actuación decidida con vistas a suprimirlas; el ciudadano que se acostumbra a simples condenas verbales de atentados por parte de quienes - pudiendo- no mueven un dedo para poner término a esos despropósitos..., ¿cómo no irán todos ellos habituándose a desproveer a la realidad de su constitutivo temple de bondad o malicia, que reclama una respuesta?, ¿cómo no habrán de finalizar por enfrentarse con las inmediaciones de la familia, el trabajo o la comunidad política con la misma radical atonía y carencia de incisividad que les imponen los medios de comunicación? ¿Cómo no habrían de retraerse a lo privado?

Porque incluso la simple aprobación o desaprobación honda y sincera de la multiplicidad de acontecimientos de los que tiene noticia sometería a cualquier subjetividad a una tensión que solo personas de especial riqueza humana son capaces de soportar.

La conclusión es evidente: se evitan las respuestas personales en los tres niveles a los que antes aludía. Y se extiende casi instintivamente ese modo de comportarse a la totalidad del propio mundo. En consecuencia, el universo así mutilado se va tornando chato, insustancial, monocorde... e incapaz a su vez de poner en resonancia a un hombre constitutivamente abierto a la verdad y al bien.

Extraigo de inmediato, muy en la línea logoterapéutica, la posible condición patógena del contacto casi exclusivo con esa realidad desprovista de ser:

Y surge, omnipresente, el aburrimiento: un tedio sin precedentes, universal, cuasi ontológico, derivado de una realidad-sin-ser. Se buscan, entonces, e incluso ansiosamente, sucedáneos: sexo, droga, emociones fuertes...

\section{En este punto, a pie de página de mi escrito de referencia, figuran las siguientes palabras de Lukas:}

Podríamos resumir los motivos existencialmente más significativos de la adicción de la siguiente manera: o bien se busca anestesia para repeler un enorme dolor, o bien se busca el "subidón" para llenar un vacío. Es decir: o bien la situación apurada se ha vuelto insalvable, o bien el aburrimiento se ha vuelto insoportable. Ambos extremos, tanto la necesidad y la pena, como la opulencia y el aburrimiento, incitan a huir de la realidad. ${ }^{26}$

\footnotetext{
${ }^{26}$ En este caso, las cursivas son mías. Transcribo la versión original: «Demnach kann man die beiden existentiell bedeutsamen Ursprungsmotive zur Sucht folgendermaßen zusammenfassen: Entweder wird die Betäubung gesucht, um einen großen Schmerz wegzudrücken, oder es wird der „Kick“ gesucht, um eine Leere zu füllen. Entweder ist Not unüberwindbar geworden, oder es ist Langeweile unerträglich geworden. Beide Extreme, Not und Leid wie Überfluss und Langeweile, verlocken zum Ausscheren aus der Wirklichkeit». LukAs, Elisabeth: Freiheit und Identität: Logotherapie bei Suchtproblemen. (Heilkunst und Lebenskunst in der Logotherapie, Band 6). 2. Aufl. München; Wien: Profil. 2005, S. 47 (tr. cast.: Libertad e identidad: Logoterapia y problemas de adicción. Barcelona: Paidós, 2005, p. 58).
} 


\section{Que es, con otros términos y en relación con el ejemplo propuesto, la misma con- clusión expresada en mi texto:}

El incomparable éxito de los denominados "culebrones" se explica en parte por cuanto ofrecen un sustitutivo a la exigencia humana de agitarse y obrar ante lo bueno y lo malo: un débil substituto que reemplaza la reacción vital y ontológica por una simple conmoción sentimentaloide, pero que ofrece al sujeto la pequeña y superficial sacudida que puede soportar una existencia sin auténtica pasión por lo real, sin pathos metafísico.

\subsection{La belleza "olvidada"}

\section{¿Qué podría decirse en relación con lo bello? Copio una vez más, omitiendo de- talles menos pertinentes, tres afirmaciones concatenadas:}

a) Siguiendo a Mouroux, estimo "que [la belleza y] el arte, bajo cualquiera de sus formas, es una necesidad esencial del hombre: que ejerce una influencia enorme sobre él y que plantea graves problemas a la sociedad moderna". ${ }^{27}$

b) Considero asimismo que, igual que para descubrir la verdad y para amar y procurar el bien, para apreciar la belleza es necesario un empeño continuado, tendente a la adquisición de un conjunto de hábitos que nos connaturalicen con lo hermoso.

Gracias a ellos se instaura además en quien los cultiva lo que conocemos como buen gusto, mesura, delicadeza en el trato con las personas y cosas, prestancia, pudor, elegancia, compostura en las situaciones más diversas, etc. ${ }^{28}$

\footnotetext{
${ }^{27}$ Mouroux, Jean: Sentido cristiano del hombre. Madrid: Palabra, 2001, p. 90.

${ }^{28}$ También en este caso, el libro contenía en pie de página un conocido pasaje frankliano, precedido de unas palabras con las que explicaba que «de nuevo la experiencia de Frankl en el campo de concentración puede servirnos de ayuda. El resumen, en lo que ahora nos atañe, podría ser: el desarrollo de la propia interioridad permite descubrir la belleza que anima todo cuanto existe incluso en las circunstancias más desesperadas. Y esa hermosura torna más llevadera la vida en su totalidad».

De inmediato copiaba el texto al que he aludido: «A medida que la vida interior del prisionero se hacía más honda, apreciábamos la belleza del arte y de la naturaleza, quizá por primera vez o con una emoción desconocida. Bajo la viveza de esas vivencias estéticas conseguíamos incluso olvidarnos de las terribles circunstancias de nuestro entorno. Si alguien hubiese visto nuestros rostros radiantes de encanto durante el viaje que nos trasladaba de Auschwitz a un campo de Baviera, cuando contemplábamos las montañas de Salzburgo, con sus picos bañados por la luz crepuscular, asomados por los ventanucos de los vagones del tren, nunca hubiese creído que se trataba de unos hombres sin ninguna esperanza de vida y de libertad. A pesar de este hecho -o quizá precisamente por esto- nos embrujaba la belleza de la naturaleza, de la que el cautiverio nos privó durante tanto tiempo. Hasta en el propio campo podía suceder que cualquiera de los prisioneros atrajese la atención de su camarada de trabajo señalándole una hermosa vista de la luz del crepúsculo a través de las altas copas de los bosques bávaros (igual que en la famosa acuarela de Durero). En esos mismos bosques nosotros construíamos un almacén de municiones secreto. Una tarde, ya de regreso en los barracones, derrengados sobre el suelo, muertos de cansancio, con el cuenco de sopa entre las manos, entró de repente uno de los internos para urgirnos a salir al patio y contemplar una maravillosa puesta de sol. Allí, de pie, vimos hacia el oeste unos densos nubarrones y el cielo entero plagado de nubes que continuamente variaban de forma y de color, desde el azul acero al rojo bermellón. Esa luminosidad menguante contrastaba de forma hiriente con el gris desolador de los barracones, especialmente cuando los
} 
c) Opino, por fin, que, como esa formación interior solo se lleva a cabo en contadas ocasiones, buena parte de lo que hoy se ofrece a nuestros semejantes como "arte" y "cultura" los incapacita para apreciar el genuino y más hondo valor de la realidad o, lo que es lo mismo, para esforzarse unitariamente por aspirar al conocimiento de lo verdadero, la realización del bien y el goce contemplativo de bellezas de más alto rango que las que frecuentan normalmente, y capaces de enriquecer de manera soberana su humanidad, a veces un tanto contrahecha.

\section{La grandeza de la persona y la actitud adecuada ante ella}

\subsection{Respeto, veneración, reverencia}

No será difícil advertir, siguiendo la tendencia implícita en lo ya expuesto, que la persona humana - "cada una de todas", como me gusta afirmar, tras las huellas de Cardona-, puesto que posee una mucho más elevada categoría de ser, reclama de las restantes personas una "respuesta" también de enorme mayor calado y la exige con muchísima más fuerza.

En este caso, tomo mis notas de un libro editado en $2009,{ }^{29}$ pero que recoge, a veces de forma casi literal, explicaciones que figuran en escritos muy anteriores. ${ }^{30}$

Las dos afirmaciones sobre las que se apoya lo que expondré a continuación son las siguientes:

a) El respeto [...] es una actitud que debe adoptarse, de manera proporcional y equitativa, tanto con las personas como con las cosas: en principio, nada de lo que existe debe ser lesionado por el hombre si no existe un motivo proporcionado para hacerlo; en semejante contexto, la gran diferencia estriba en que, tratándose de personas, nunca puede darse un motivo de tal calibre que guarde proporción con una afrenta contra la dignidad.

b) Por el contrario, la veneración y la reverencia se dirigen de modo más propio a las personas.

Cuestiones que ilustro poco más adelante:

[...] hablar de respeto al ser humano, aunque correcto y aceptable, resulta bastante pobre, se queda corto. Respeto lo merece todo lo que es en el grado o medida en que es: según su rango.

Pero la dignidad de la persona reclama ese nivel supremo o magnificación del respeto que conocemos como veneración o reverencia.

charcos del suelo fangoso reflejaban el resplandor de aquel cielo tan bello. Luego, tras unos minutos de silencio y emoción, un prisionero le dijo a otro: “Qué hermoso podría ser el mundo...!”» FrankL, Viktor E.: Man's Search for Meaning, cit., p. 59-60 (tr. cast., pp. 67-68).

${ }^{29}$ Melendo, Tomás: Invitación al conocimiento del hombre. Madrid: Ediciones Internacionales Universitarias, 2009.

${ }^{30}$ Por ejemplo, y refiriéndome exclusivamente a libros, en Melendo, Tomás: Las dimensiones de la persona. Madrid: Palabra, 19991 2002². IDEM: Introducción a la antropología: la persona. Madrid: Ediciones Internacionales Universitarias, 2005. 
Y si estas afirmaciones suenan un tanto exageradas es justo porque, a pesar de que se pregone constantemente, o tal vez por esa misma causa, hemos perdido en buena parte la sensibilidad que permite captar en toda su hondura la grandeza, el carácter sagrado, de la persona... de cualquier persona, incluso de la más autodegradada.

De hecho, Agustín de Hipona y Séneca fundamentaban la veneración debida al enfermo calificando a este como "res sacra miser», como algo sagrado en un estado penoso o miserable [digno de com-pasión].

La índole sagrada del paciente está clara, y constituye el trasunto de su nobleza personal. La condición lamentable, por su parte, no añade un incremento de excelencia respecto al individuo sano, pero parece exigir mayor veneración y miramiento en el trato con él, justo por su extrema vulnerabilidad. Puesto que la dignidad del enfermo se encuentra momentánea y más o menos gravemente amenazada, reclama un suplemento de consideración.

Como podemos comprobar por contraste en el mundo actual, la reverencia o el respeto a los más débiles constituye el test o la piedra de toque para medir hasta qué punto una concreta cultura ha profundizado y se toma en serio las exigencias de la dignidad personal.

\subsection{Principio y término de amor}

Cabe todavía un nuevo paso, en parte fundamentado en los comienzos de este mismo artículo: el que afirma que, en definitiva, la única actitud adecuada ante la persona no es el respeto, como ya dije, pero tampoco la veneración o reverencia; sino que, englobando y trascendiendo a todas ellas, se encuentra constituida exclusivamente por el amor, que sabe y se empeña en buscar el bien del otro. ${ }^{31}$

La explicación es relativamente sencilla y también la he esbozado: toda persona merece ser amada precisamente porque ella, poniendo entre paréntesis su propio beneficio, puede y tiende a ocuparse del bien de quienes lo rodean, es decir, se encuentra por naturaleza inclinada a amar.

En efecto, tal como afirma Berti, la mejor filosofía clásica enseña que la persona es lo más perfecto, lo "perfectísimo" que existe en la naturaleza (perfectissimum in tota natura) ${ }^{32}$ que solo a las realidades más nobles, las de más talla, se aplica ese califi-

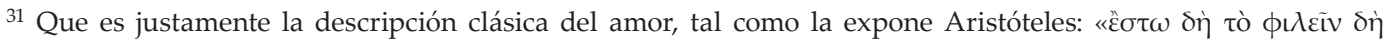

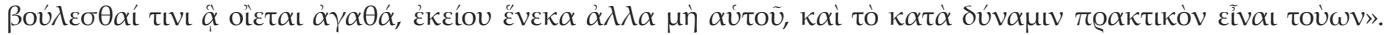
Aristóteles: Retórica. Lib. II, cap. 4, 1380b 35-36 (tr. cast.: Madrid: Gredos, 1990, p. 327).

32 «Colui che ha tratto alla luce nel modo più completo tutte le potenzialità implicite nella classica definizione boeziana della persona, è indubbiamente san Tommaso d'Aquino. Questi anzitutto l'ha ripresa, sottolineandone l'altezza del significato, ma anche introducendovi una significativa precisazione: "persona significat id quod est perfectissimum in tota natura, scilicet subsistens in rationali natura" (S. Th., I, q. 29, a. 3); oppure: "modus existendi quem importat persona est dignissimum, ut scilicet aliquid per se existens" (De pot., q. 9, a.4)». BERTI, Enrico: Il concetto di persona nella storia del pensiero filosofico; Berti, Enrico; Cottier, Georges; PIAna, Giannino; et alii: Persona e personalismo. Padova: Fondazione Lanza, 1992, p. 49.
} 
cativo; y que les corresponde precisamente a causa de su superioridad entitativa. Y después de algunas otras consideraciones, concluye: justo por su eminente grandeza, esa excelencia en cierto modo se desborda, rebosa fuera de sí; por consiguiente, lo que caracteriza a la persona en cuanto persona es el don, la fecundidad, la entrega.

Quizá resulte más inteligible mediante una comparación, que prosigue los textos antes citados:

a) Las realidades infrapersonales - un animal, una planta- gozan de tan poca entidad, son "tan poca cosa", que toda su actividad han de encaminarla a mantenerse en el ser, a asegurar la tenue realidad que las constituye como fragmento o eslabón de su especie. De ahí la importancia capital, decisiva entre ellas, de lo que hoy conocemos como principio o instinto de conservación (individual y específico), que las refiere inevitablemente a sí o a su especie en cuanto suya.

b) Por el contrario, la persona posee una sublime consistencia entitativa. En su núcleo, es siempre espiritual: recibe en sí y por sí, y no en la materia, el propio acto de ser. ${ }^{33}$ Esto quiere decir que su principio constitutivo más íntimo, su actus essendi, al no encontrarse intrínseca y definitivamente disminuido por la materia, conserva de manera supereminente, junto con su extremada riqueza y virtual perfección, ${ }^{34}$ la efusividad que por naturaleza le corresponde; puesto que todo acto, en la exacta proporción en que lo es, tiende a comunicarse, el «acto personal de ser», 35 acto en la acepción más plena, no solo resulta «activo de suyo», ${ }^{36}$ sino intrínsecamente expansivo,

${ }^{33}$ En relación a este extremo, cf. Melendo, Tomás: “Metafísica de la dignidad humana”; Anuario Filosófico, 1994 (27/1), pp. 25 ss.

${ }^{34}$ Parece oportuno traer expresamente a colación el capital texto de Tomás de Aquino: «Omnis autem nobilitas cuiuscumque rei est sibi secundum suum esse: nulla enim nobilitas esset homini ex sua sapientia nisi per eam sapiens esset, et sic de aliis. Sic ergo secundum modum quo res habet esse, est suus modus in nobilitate: nam res secundum quod suum esse contrahitur ad aliquem specialem modum nobilitatis maiorem vel minorem, dicitur esse secundum hoc nobilior vel minus nobilis. Igitur si aliquid est cui competit tota virtus essendi, ei nulla nobilitatum deesse potest quae alicui rei conveniat. Sed rei quae est suum esse, competit esse secundum totam essendi potestatem: sicut, si esset aliqua albedo separata, nihil ei de virtute albedinis deesse posset; nam alicui albo aliquid de virtute albedinis deest ex defectu recipientis albedinem, quae eam secundum modum suum recipit, et fortasse non secundum totum posse albedinis. Deus igitur, qui est suum esse, ut supra probatum est, habet esse secundum totam virtutem ipsius esse. Non potest ergo carere aliqua nobilitate quae alicui rei conveniat». Tomás DE Aquino: C. G. I, c. 27, nn. 259-260.

${ }^{35}$ La formulación es de Cardona: «Todo eso deriva también de lo que he llamado "acto personal de ser", con una expresión que no me consta que nadie hubiese utilizado antes, pero que entiendo perfectamente armónica -si no en recíproca y necesaria pertenencia - con la noción propia de acto de ser, tal como Tomás de Aquino la formuló, y con su consiguiente noción de persona». CARdona, Carlos: Olvido y memoria del ser. Pamplona: Eunsa, 1997, p. 318. 36 Cardona, Carlos: Metafísica del bien y del mal. Pamplona: Eunsa, 1987, p. 30 y passim. La índole activa del actus essendi representa, desde el punto de vista de los fundamentos, la verdad primordial de este escrito. 
que viene a ser lo mismo: cuando el ser alcanza cierta cota (la propia de la persona), asegurado ya en sí, se "vuelve" naturalmente hacia afuera. ${ }^{37}$

Conclusión, también de enormes consecuencias para la vida cotidiana: la persona demuestra y confirma su preeminencia en el ser, su mayor rango ontológico, en que puede y debe desatenderse, olvidarse de sí misma, para volcar toda su energía en la afirmación de aquellos que la rodean. ${ }^{38}$ Porque es mucho, porque su acto de ser no se encuentra disminuido por la materia, no necesita ya ocuparse de sí, puede y debe -repito con Spaemann- ponerse libremente entre paréntesis, des-considerarse, y atender al perfeccionamiento de los otros. ${ }^{39}$ Solo entonces, al asumir voluntariamente

\footnotetext{
${ }^{37}$ Vienen muy a cuento las palabras de Brock: «What is more, the thesis that every agent acts for its own good, or in the maintenance and promotion of its own form, also shows that the principle of finality does not always mean that an agent acts to get some good, of acts out of need. Rather, to the very extent that it is an agent, it already possesses the good on account of which it acts. Indeed, if the end for whit I an agent acts is precisely a share in its own form, then every agent acts $\mathrm{h} \mathrm{r}$ its own good; and its first inclination toward this good is not expressed in its outward action at all, but in its own remaining what it is, its persisting. To say that when it acts, it acts for its own good means that it acts to give, to promote the good that it already enjoys. Power is wealth, not penury. If an agent only acts, only gives or provides, in order to receive, then it is an imperfect, not fully formed agent. It is once the agent receives what it needs and is made perfect, is fully formed, that it is able to act to the highest degree, to give of itself most unrestrictedly». ВRоск, Stephen L.: Action and conduct: Thomas Aquinas and the Theory of Action, Edinburg: T\&T Clark, 1998, p. 118-119. (tr. cast.: Acción y conducta: Tomás de Aquino y la teoría de la acción. Barcelona: Herder, 2000, pp. 150-151).

${ }^{38}$ Como puede advertirse, estas afirmaciones se hallan en la misma línea que la autotrascendencia de Frankl, que marca un sentido claro y una orientación neta para la responsabilidad del ser humano: la salida de sí mismo. Así lo explica Frankl: «Al declarar al hombre un ser responsable y capaz de descubrir el sentido concreto de su existencia, quiero acentuar que el sentido de la vida ha de buscarse en el mundo y no dentro del ser humano o de su propia psique, como si se tratara de un sistema cerrado. La misma argumentación permite afirmar que la auténtica meta de la existencia humana no se cifra en la denominada autorrealización.

La autorrealización por sí misma no puede situarse como meta. No debe considerarse el mundo como simple expresión de uno mismo, ni tampoco como mero instrumento, o como un medio para conseguir la ansiada autorrealización. En ambos casos la visión del mundo, o Weltanschauung, se convierte en Weltentwertung, es decir, menosprecio del mundo.

A esta característica esencial del hombre la designé "autotrascendencia de la existencia": ser hombre implica dirigirse hacia algo o alguien distinto de uno mismo, bien sea realizar un valor, alcanzar un sentido o encontrar a otro ser humano. Cuanto más se olvida uno de sí mismo - al entregarse a una causa o a una persona amada - más humano se vuelve y más perfecciona sus capacidades. En efecto, cuanto más se afana el hombre por conseguir la autorrealización más se le escapa de las manos, pues la verdadera autorrealización solo es el efecto profundo del cumplimiento acabado del sentido de la vida. En otras palabras, la autorrealización no se logra a la manera de un fin, más bien como el fruto legítimo de la propia trascendencia». FrankL, Viktor E.: Man's Search for Meaning, cit., p. 132-133 (tr. cast., pp. 132-123).

39 «Der Mensch ist das Wesen, das sich selbst zurücknehmen, sich relativieren kann. Er kann, wie es in der christlichen Sprache heißt, „,sich selbst sterben“ [...]. Eben in dieser Relativierung des eigenen endlichen Ich, der eigenen Begierden, Interessen und Absichten erweitert sich die Person und wird ein Absolutes. Sie wird inkommensurabel. Sie kann sich selbst in den Dienst einer ihr zunächst fremden Sache stellen bis hin zum Selbstopfer». SPAemann, Robert: Das Natürliche und das Vernünftige: Aufsätze zur Anthropologie, München: R. Piper GmbH \& Co. KG, 1987, S. 90 (tr. cast.: Lo natural y lo racional. Madrid: Rialp, 1989, p. 104).
} 
el impulso o la inclinación más radical que reside en ella ${ }^{40}$ se cumple como persona y, como consecuencia, es feliz o dichosa.

\section{Correspondencia familia-persona y viceversa}

\subsection{Razones de "grandeza"}

Ahora bien, según expondré enseguida, para que una persona pueda de veras entregarse se requieren otra $u$ otras que la acojan libre, incondicionada e incondicionablemente. $\mathrm{Y}$ esa acogida gratuita y sin reservas tiene lugar, de manera muy particular y casi exclusiva, en el seno de la familia o en aquellas otras realidades que se configuren formalmente como tal.

De ahí que, en contra de una opinión bastante difundida, la razón más honda de la existencia de la familia sea justo la grandeza de la persona, que, en virtud de su exceso de ser, para cumplir con lo que exige su misma condición personal, para (llegar a) ser una persona cabal, necesita darse. ${ }^{41}$

Lo cual, con toda probabilidad, produzca cierta extrañeza en el lector. Y es que, habitualmente, se nos induce a pensar que el único y principal fundamento de la familia son las carencias propias del ser humano. ¿Por qué considero esta explicación insuficiente? Porque, aunque lo que sostiene es cierto, no se adentra hasta el núcleo de la cuestión.

En efecto, si a lo largo de todo el artículo he insistido en que "persona" es sinónimo de grandeza y dignidad, y si la familia debe concebirse -y de hecho así se considera- como una institución nobilísima, ¿no resulta un tanto absurdo que los animales, claramente inferiores al hombre, no tengan necesidad de ella, mientras que el hombre sí la reclame, pero en virtud de su indigencia?; ¿no lo transformamos de este modo en "algo" de menor categoría que los animales con los que se compara?

Volvamos, pues, a la razón antes expuesta, intentando comprenderla más hondamente. Con terminología especializada, pero susceptible de ser entendida en cuanto se la ilustre con algún ejemplo, cabría razonarlo siguiendo una célebre y profunda afirmación de Aristóteles, que repiten sus seguidores latinos: la que sostiene que actio agentis est in passo, que la acción del que obra "está" en el paciente o acaba de

\footnotetext{
40 «L'amour est d'une certaine manière naturel à l'homme, celui-ci a été créé pour aimer, et porte une aspiration profonde à se donner. [Y en nota] Même si on en a rarement conscience, le besoin le plus profonde de l'homme est sans doute celui de se donner». Philippe, Jacques: La liberté intérieure. $7^{7}$ éd. Burtin, Nouan-le-Fuzelier: Ed. des Béatitudes, 2002, p. 118 (tr. cast.: La libertad interior. 3aㅡ ed., Madrid: Rialp, 2004, p. 122 y nota 15).

${ }^{41}$ Es lo que denomino "necesidad por exceso".
} 
cumplirse o ser en él. ${ }^{42} \mathrm{Y}$ así, por acudir a un caso un tanto drástico, no puede decirse que alguien mate a otra persona, por más que lo intente y dispare a bocajarro sobre ella, si el "paciente" no llega a morir. Del mismo modo, y en sentido estricto, ningún profesor, por más brillante que fuere, puede enseñar nada si no existe al menos un alumno que aprenda algo gracias a sus explicaciones.

Aplicándolo a la persona, destinada por naturaleza al amor, y como ya dejé dicho, nadie puede entregarse si no existe algo capaz de recibirlo y lo recibe de hecho; o, más bien, si no encuentra "alguien", otra persona, dispuesta a hacerlo. Y esto, por dos motivos:

a) Antes que nada, porque ninguna realidad inferior a una persona es susceptible de acoger o albergar la grandeza de otra persona.

b) Además, porque si hablamos de verdadera entrega, la "pasión" correspondiente, por expresarlo de un modo sin duda impropio, "se torna activa". En términos estrictos, puliendo el modo de decir, una persona no "es recibida" por otra sino en cuanto que esta segunda la acoge o acepta con un acto eminente de libertad: es decir, con el acto más activamente activo.

Habría, pues, que reflexionar más, y tal vez que corregir, la concepción de los dos integrantes de una relación amorosa como "activo" y "pasivo". Una vez que se advierte lo que acabo de insinuar, la acogida del otro manifiesta una suprema actividad, como también - salvando las distancias- cualquier acto de libertad por

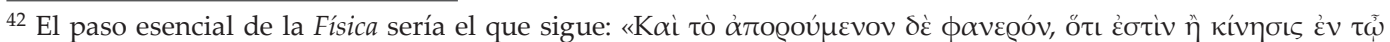

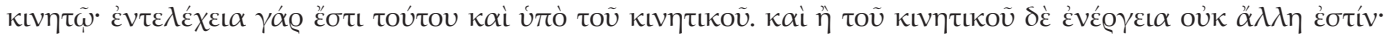

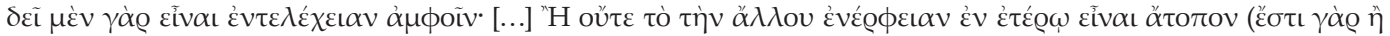

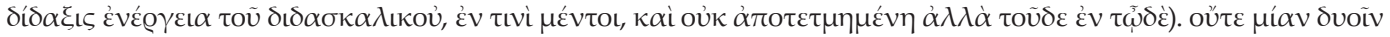

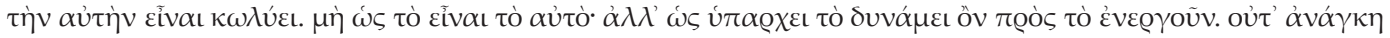

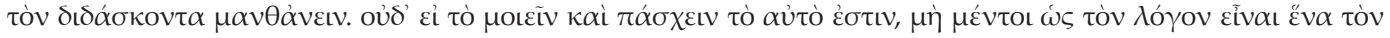

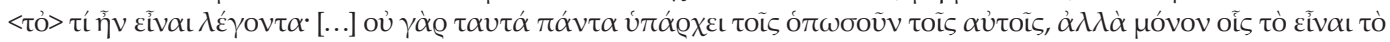

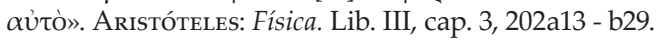

Así lo comenta Brock: «In at least some actions, the agent is one thing, and that of which it is the agent, e.g. a change, belongs to something else. This fact forced Aristotle through a series of reflections on the relation between agent, patient and change, until he arrived at the remarkable formulation 'the actuality of the agent (qua agent) is in the patient'. This means that that relative to which the agent is called an agent, namely its action, comes to completion Hi terminates, not in the agent itself (again, qua agent), but in the patient. It is the patient that is changed. The change is called a change insofar as attention is focused simply on its character of bridging the contrary terms dint constitute its beginning and its end. It is called a passion insofar as it to seen as received by the patient from an agent. The same change is called au action, insofar as it is seen as initiated by the agent in the patient. Thus the action of the agent, that of which it is called the agent, does not terminate or come to completion in the agent at all, but in the patient. Only if the agent is also the patient is it the subject in which its action terminates». BROCK, Stephen L.: Action and conduct, cit., p. 53 (tr. cast.: Acción y conducta, cit., p. 74).
} 
el que se acepta gozosamente incluso aquello que, por otro lado, no podría evitarse: nos encontramos muy cerca de los franklianos "valores de actitud". ${ }^{33}$

En todo caso, resulta bastante claro que la causa fundamental por la que el ser humano reclama la familia se basa en la excedencia o magnificencia que le compete por su condición de persona y no, de manera primaria, en ningún tipo de indigencia o déficit.

\subsection{La limitación de lo finito}

\subsubsection{En función de las carencias}

Advertir esta inversión resulta revolucionario, no sólo en la teoría, sino sobre todo en la práctica, en la vida cotidiana. Pues la primera y más fundamental consecuencia vendría a ser la que sigue: cuanto más se desarrolle una persona, cuanto más pueda considerarse un triunfador o una triunfadora en función de los parámetros al uso, más necesidad tendrá de la familia como ámbito genuino de su auténtico desarrollo como persona y, por ende, de su felicidad. ${ }^{44}$

No es, por tanto, la familia una suerte de refugio para los más débiles: los nonacidos, los niños, los enfermos, los ancianos..., sino el lugar de la auténtica personalización de todo ser humano, más imprescindible conforme mayor se torna el desarrollo y plenitud que este vaya adquiriendo. La razón, como he repetido, es que la familia no encuentra su primer y más radical fundamento en indigencia alguna. La última razón es la "grandeza y sublimidad" del ser que por naturaleza corresponde a cualquier persona, que le "exige" amar y también -derivadamente, como condición de posibilidad de su entrega- que alguien acoja el amor con que se da.

Esto no elimina, sin embargo, otros motivos que explican la existencia de las familias humanas. En concreto, las razones que se enumeran de ordinario, aparejadas a las carencias constitutivas de los varones y mujeres: las fisio-biológicas, las "funcionales" y las psico-espirituales, que son las más hondas y decisivas. Es decir, ordenadamente:

\footnotetext{
43 «L'acte le plus haut et le plus fécond de la liberté humaine réside davantage dans l'accueil que dans la domination. L'homme manifeste la grandeur de sa liberté quand il transforme la réalité, mais plus encore quand il l'accueille avec confiance telle qu'elle lui est donnée jour après jour». PhiLIPpe, Jacques : La liberté intérieure, cit. p. 26 (tr. cast., p. 30).

${ }^{44}$ Cuanto estoy exponiendo se encuentra también escrito, entre otros, en un libro que se remonta al año 1995: MELENDO, Tomás: La hora de la familia. $4^{a}$ ed., Pamplona: EunSA, 2008.
} 
a) Su precariedad biológica, muchísimo más manifiesta durante los primeros meses y años de vida y más todavía, en cierto modo, mientras permanece en el seno materno.

b) La incapacidad para realizar por sí solos todas las tareas indispensables para la supervivencia.

c) Y la aún más honda y perentoria urgencia de superar la soledad y llevar una vida propiamente humana -el buen vivir o vivir bien, al que se referían los griegos clásicos-, con todo lo que eso implica, y que únicamente es posible al relacionarse con otras personas.

Pero, según he sugerido, estas últimas razones derivan no tanto del carácter personal de los seres humanos, sino de la finitud que les compete en cuanto personas limitadas.

\subsection{2. ¡Para hacer posible el amor!}

Lo cual trae a su vez dos consecuencias, que también vale la pena señalar:

a) La primera, ya apuntada, que el conjunto de actividades específicamente ligadas a esa limitación - como el alimento, el cobijo, el imprescindible descanso y tantas otras - se oriente y encuentre todo su sentido en el amor inteligente, en la entrega de sí, que es lo característico de la persona como tal.

b) La segunda es la que ahora más nos interesa. Justo por su finitud, los varones y mujeres necesitamos asimismo de la familia, en el sentido a la vez propio y más lato de esta palabra, para obtener los recursos imprescindibles que nos permitan actuar como personas: es decir, en continuidad con lo que vengo repitiendo, para (aprender a) amar de la manera adecuada, eficaz e inteligente.

De lo que cabe de nuevo concluir, pero con un motivo añadido, que la familia es el ámbito primordial de personalización de cualquier varón y mujer. El lugar donde nace, vive y muere, precisamente como persona. $\mathrm{O}$, si se prefiere, el hábitat donde va creciendo como persona y donde día tras día repone las fuerzas imprescindibles para actuar en medio del mundo... también como persona, como principio y término de amor. Afirmación que nos introduce directamente en la última parte de nuestro escrito y en el tema central de estas Jornadas. 


\section{El cuidado}

\subsection{Familia, amor, cuidado}

Resumo: si cualquier persona precisa de la familia fundamentalmente para dar amor y entregarse, también la requiere - de manera secundaria- para ser incondicionalmente amada y, de este modo, adquirir y re-adquirir el vigor imprescindible con que llevar a término esa operación suprema y sumamente caracterizadora, que es el amor sin reservas.

Lo que equivale a sostener que, al llevar hasta sus últimas consecuencias la célebre afirmación aristotélica que califica al hombre como "social", la persona es intrínsecamente un ser-familiar, y que el perfeccionamiento de la persona y el de la familia se encuentran ligados de manera esencial e indisoluble, hasta el punto de que no puede establecerse prioridad alguna de una sobre otra: ni existe familia sin persona... ni puede darse una persona cabal, cumplida, plenamente desarrollada, sino en un contexto familiar, en el sentido amplio antes utilizado. Por consiguiente, atendiendo a su misma naturaleza - o de derecho, si se prefiere esta expresión-, ni la persona es anterior a la familia ni la familia es anterior a la persona. No obstante, de facto, en la vida vivida, sí que cabría hablar de cierta prioridad. Pero prioridad... ¡de la familia sobre la persona!, por más que de nuevo resulte extraño.

Pues si la persona es principio y término de amor, y si la familia constituye el ámbito natural donde el ser humano debe amar y ser amado de manera incondicional -incondicionada e incondicionable- por el simple-sublime hecho de ser persona, y donde efectivamente aprende a hacerlo, la familia compone el núcleo y el origen de la más honda y genuina humanización de la humanidad.

Por eso ha podido decirse que civilizar equivale a hacer familiar lo (inicialmente) no familiar. Lo que viene a significar que la auténtica cultura, el cultivo y desarrollo de lo más personal de la persona humana, es la que enseña e inclina a instaurar entre todos los hombres genuinas relaciones de amor.

Pero el auténtico amor humano, aquel al que antes aludía con palabras de Aristóteles, aunque constituido esencialmente por un acto voluntario y libre, que busca con decidida decisión el bien del otro en cuanto otro, no pone en juego sólo la voluntad. ${ }^{45}$ Cualquiera que esté enamorado sabe que el amor humano implica a la persona entera: lo que es, lo que hace, lo que tiene, lo que anhela...

\footnotetext{
${ }^{45}$ Sigo en estos últimos párrafos, fundamentalmente, Melendo, Tomás: El verdadero rostro del amor. Madrid: Ediciones Internacionales Universitarias, 2006.
} 
Y la razón es sencilla. Como el resto de nuestras facultades, también la voluntad del hombre es limitada. De modo que, por muy sincera y honda que sea la decidida decisión voluntaria de buscar el bien de la persona querida, ese acto no es, por sí mismo, eficaz: no logra sin más el bien que persigue. Como consecuencia, tiene que "completarse" y proseguirse por otros que lo consuman y manifiestan, y por el conjunto de actividades con que efectivamente "da vida" al bien del otro: lo construye y se lo entrega. ${ }^{46}$

Entre las segundas acciones - las que tienden a "confeccionar" el bien del amado-, ocupa un lugar preponderante y prioritario el trabajo: el esfuerzo constante y concienzudo por construir bienes para los otros $\mathrm{y}$, a fin de cuentas, para la entera humanidad. De ahí que el trabajo haya sido descrito como "el incógnito del amor". ${ }^{4}$

A su vez, el querer meramente voluntario, que correría el peligro de transformarse en algo frío, duro y carente de auténtica humanidad, alcanza su plenitud mediante los múltiples afectos que hacen de él algo tierno y jugoso, así como a través de los gestos con que damos a conocer nuestro cariño a quien amamos: sonrisas, miradas comprensivas, abrazos y caricias, confidencias, apertura de la intimidad, detalles de servicio, escucha reposada...

\footnotetext{
${ }^{46}$ También en este punto existe una clara analogía con la doctrina al respecto de Frankl (con unas asimismo claras diferencias, en las que no quiero detenerme). Por ejemplo: «De lo dicho se desprende que la persona espiritual no es capaz de imponerse incondicionadamente a través de las capas psicofísicas. Ni la persona espiritual está siempre manifiesta a través de las capas psicofísicas, ni tampoco es siempre eficiente. Bien es verdad que el organismo psicofísico es un conjunto de órganos, de instrumentos, y por lo tanto, de medios para un fin. Este fin es doble, conforme a las dos funciones del organismo frente a la persona espiritual: su función expresiva y su función instrumental; y el organismo es un medio para este doble fin al servicio de la persona. Pero este medio -en cuanto a su función expresiva - es turbio y - en cuanto a su función instrumental- es inerte. Precisamente por su turbiedad la persona espiritual no es siempre visible a través del medio del organismo posible y por su inercia tampoco es siempre eficaz. En resumen, este medio al servicio de la persona carece de las cualidades necesarias a una servidumbre perfecta; la potentia oboedientialis está de algún modo rota, ha sufrido algún deterioro (con palabras de mi asesor teológico el desaparecido doctor Leopold Soukup). De modo que también podría hablarse, dado el caso, de una impotentia oboedientialis. De todas formas, no puede decirse que el organismo psicofísico, o todos los fenómenos morbosos que se dan en él, sea representativo de la persona espiritual que está detrás y que se sirve de él de una manera o de otra, puesto que no es capaz de lo último en toda condición y circunstancia». FranKL, Viktor E.: Theorie und Therapie der Neurosen, cit. S. 82 (tr. cast., pp. 118-119).

47 «En consommant ce que nous avons produit, en absorbant et assimilant notre travail pour le transsubstantier en sa propre vie, c'est de nos propres forces, de notre propre temps, de notre propre vie qu'autrui nourrit et développe la sienne. En échangeant les produits de notre travail, c'est donc la substance de nos vies que nous échangeons, que nous transfusons. Pour autant que notre travail pourvoit à l'attente et aux besoins d'autrui, la joie qu'il nous inspire est donc véritablement eucharistique: "prenez et mangez-en tous, car ceci est mon corps". Telle qu'elle est évoquée par Marx, la joie du travail serait donc analogue à l'effusion amoureuse. Comme l'amour, le travail consisterait en effet à donner sa vie, et à susciter par ce seul don l'allégresse d'une autre vie. Mais, à la différence de l'amour, s'il est bien aussi une manière de donner irréversiblement sa vie, sans reste, sans réserve, c'est toutefois sans imposer sa personne. Sous sa forme anonyme, silencieuse, effacée et discrète, le travail est l'incognito de l'amour». GRIMALDI, Nicolás : Le travail : Communion et excommunication. Paris : PUF, 1998, p. 135-136.
} 
Pues bien, sin forzar excesivamente la realidad, cabría decir que el "cuidado", tanto en su acepción común como en la más específica de las situaciones de enfermedad y otras carencias, constituye una estupenda síntesis de todo lo anterior:

a) de la decisión libre y voluntaria de otorgar a los otros aquellos bienes que en ese momento necesitan (es decir la esencia o "columna vertebral" del amor);

b) de los actos con los que de hecho se persigue y procura ese beneficio para el ser querido;

c) y de los afectos - manifestados de forma expresa, aunque a veces nos venza el cansancio- que "humanizan" todo lo anterior, hasta poner en contacto directo y explícito lo más noble y personal de quien cuida y de quien es cuidado.

De tal suerte, el cuidado "condensa" en cierto modo la esencia de la familia y de la persona, destinada por naturaleza a amar y a acoger libremente el amor que le ofrendan, en sus múltiples manifestaciones. El que cuida descubre el sentido de su tarea en cuanto gracias a ella - al amar activamente- se cumple como persona; y el que es cuidado, si se le explica del modo oportuno, está en condiciones de percibir un doble sentido en su "dejarse cuidar": pues no sólo ama al recibir gratuitamente el amor que gratuitamente le ofrendan, sino que, al hacerlo, facilita el pleno amor de quien lo cuida.

Si cuidar puede y debe considerarse como una sublime encarnación del amor, ser cuidado la eleva "a la segunda potencia". Pues, como veíamos páginas atrás -actio agentis est in passo-, la acción del agente sólo alcanza su plenitud en virtud de quien recibe sus frutos: por tanto, si la persona cuidada no se dejase cuidar, tampoco el que cuida podría real y acabadamente amar a quien tiene a su cuidado; una conclusión sin duda paradójica, pero cierta cuando se examina con todo su hondura.

\subsection{El cuidado en la logoterapia}

Tampoco me parece forzado relacionar esta realidad con una de las ideas más de fondo que ha acompañado a Frankl durante toda su existencia y que dio título al primero de sus libros manuscritos: la "ärztliche Seelsorge", que en castellano suele traducirse como "cura de almas", pero que apunta a lo más personal de cada persona y cuya rehabilitación constituye una de las mayores aportaciones de la logoterapia.

Respecto a ella escribía Frankl en 1981 unas palabras que deberían tal vez hacernos reflexionar:

Lo que nosotros apenas nos atrevemos a expresar con palabras, nuestros pacientes lo convierten en acción. Incluso in extremis e in ultimis arrancan un sentido a la vida. Lo que nos queda 
- en el marco de tal lucha por un sentido-, consiste en prestar una ayuda catalítica, una "cura de almas médica", si así se quiere decir. ${ }^{48}$

Tras lo cual, sólo me queda concluir con uno de los muchos ejemplos en que se hace vida todo lo anterior, así como los rasgos centrales de la logoterapia. Ante todo, Frankl expone la situación:

Vamos a ejemplificar la necesidad y la posibilidad de la "cura de almas" médica con un caso quirúrgico: se plantea operar a una enfermera de mi estación y de las pruebas resulta como inoperable. En su desesperación la enfermera me llama para hablar con ella. De la conversación resulta que no está desesperada tanto por su enfermedad como por su incapacidad de trabajar: ella ama su profesión por encima de todo, pero ahora ya no puede ejercerla.

\section{Pasa de inmediato a abrir posibilidades de sentido:}

¿Qué habría tenido que decir frente a esta desesperación? La situación de esta enfermera no tenía realmente salida. (Murió una semana después.) Sin embargo, intenté explicarle que el hecho de que ella trabajase ocho o Dios sabe cuántas horas al día, no era ningún arte - esto lo puede hacer cualquiera-; pero estar tan dispuesta al trabajo como ella y ser a la vez tan incapaz - sin desesperar a pesar de ello - sería un resultado, le dije, en el que nadie sería capaz de imitarle tan pronto. Y le seguí preguntando si en el fondo no cometería una injusticia en relación con todos los miles de enfermos a los que ella había dedicado su vida como enfermera: si no cometería ninguna injusticia en relación con ellos si en este momento se comportase como si la vida de un enfermo o de una persona achacosa, o sea, de un hombre incapaz de trabajar, careciera de sentido. Tan pronto como Ud. desespera en su situación, le dije, hace como si el sentido de una vida humana dependiera del hecho de que una persona pueda trabajar tantas horas; niega con ello a todas las personas enfermas y achacosas cualquier derecho a la vida y cualquier justificación de la existencia.

Y cierra con una afirmación que descubre el mejor sentido de cuanto he intentado exponer en este artículo:

Precisamente ahora tiene Ud. una oportunidad única: mientras que hasta ahora Ud. no pudo prestar nada más que asistencia profesional a todos los hombres que le fueron confiados, ahora tiene Ud. la oportunidad de ser más: un modelo humano. ${ }^{49}$

\footnotetext{
${ }_{48}$ Transcribo la cita original: «Was wir kaum in Worte zu fassen wagen, wird von unseren Patienten in die Tat umgesetzt. Sie ringen dem Leben selbst in extremis und in ultimis extremis einen Sinn ab. Was aber uns bleibt, ist -im Rahmen solchen Ringens um Sinn -, eine katalytische Hilfestellung zu leisten, »ärztliche Seelsorge«, wenn Sie so wollen». FrankL, Viktor: „Psychologisierung - oder Humanisierung der Medizin?“ (1981); Logotherapie und Existenzanalyse: Texte aus sechs Jahrzehnten, cit., S. 238 (tr. cast.: “Psicologización o humanización de la medicina?”; Logoterapia y análisis existencial: Textos de cinco décadas, cit., p. 253).

${ }^{49}$ FrankL, Viktor: „Grundriß der Existenzanalyse und Logotherapie“ (1939), cit., S. 124 (tr. cast., p. 132).
} 